\title{
CONTAMINAÇÃO POR STAPHYLOCOCCUS AUREUS NOS CHASSIS RADIOGRÁFICOS EM HOSPITAL DE ENSINO
}

\author{
Eduarda Vilas Boas Castro, Nadia Araujo Miguel
}

Universidade do Oeste Paulista - UNOESTE, Curso Superior de Tecnologia em Radiologia, Presidente Prudente, SP. Email: nammiguel@hotmail.com

\section{RESUMO}

Uma das ações rotineiras em um hospital é a realização de exames de raios $X$, onde são utilizados chassis radiográficos não descartáveis em pacientes distintos. Este estudo objetiva investigar esses chassis de uso comum, como veículos de infecção hospitalar, ajudando na disseminação de Staphylococcus spp. quanto à prevenção e controle de infecção hospitalar. O estudo foi realizado em um hospital de ensino no interior de São Paulo, foram estudados dois chassis radiográficos $(18 \times 24 \mathrm{~cm})$ e obtidas amostras para as culturas de dois destes chassis, em três momentos diferentes. Foram observados presença de unidades formadoras de colônia (UFC) de Staphylococcus spp., sendo que no chassi 1, 14,43\%, e no chassi 2, 1,37\% das colônias apresentaram a prova da coagulase positiva indicando ser Staphylococcus aureus. Propõe-se a padronização de um procedimento operacional de higienização para esses chassis radiográficos na tentativa de minimizar o risco de contaminação bacteriana por Staphylococcus spp.

Palavras-chave: chassis, contaminação bacteriana, Staphylococcus aureus.

\section{CONTAMINATION BY STAPHYLOCOCCUS AUREUS IN RADIOGRAPHIC CHASSIS TEACHING HOSPITAL}

\begin{abstract}
One of the routine actions in a hospital is performing $x$-rays, which are used radiographic chassis nondisposable in different patients. This study aims to investigate the chassis of common use, such as hospital infection vehicles, helping the spread of Staphylococcus spp. on the prevention and control of hospital infection. The study was conducted in a teaching hospital in São Paulo, two radiographic chassis $(18 \times 24 \mathrm{~cm})$ were studied and samples obtained for the cultures of these two chassis in three different times. The presence of colony forming units (CFU) of Staphylococcus spp. was observed and the chassis 1, 14.43\%, and the chassis $2,1.37 \%$ of the colonies showed evidence of positive coagulase indicating that Staphylococcus aureus. It is proposed the standardization of the operating procedure for cleaning these radiographic chassis in an attempt to minimize the risk of bacterial contamination by Staphylococcus spp.
\end{abstract}

Keywords: chassis, bacterial contamination, Staphylococcus aureus.

\section{INTRODUÇÃO}

Os Staphylococcus são as bactérias mais resistentes no meio ambiente com capacidade de sobreviver por meses em amostras clínicas secas e são relativamente resistentes ao calor e tolerantes a altas concentrações salinas. Entretanto, apesar dos antimicrobianos existentes, da melhoria nas condições sanitárias e das medidas de controle de infecção hospitalar, este microrganismo continua a ser um dos mais importantes agentes patogênicos para 0 homem $^{1}$.
A presença de microrganismos nas superfícies, assim como a microbiota normal não oferecem riscos ao homem, mas se houver alguma imunodepressão, esses microrganismos podem se tornar patogênicos. Assim, objetos muito usados sem higiene e em contato com várias pessoas podem se tornar focos de contaminação ${ }^{2}$.

Estudos microbiológicos realizados em aparelhos hospitalares tem demonstrado a presença de diversos tipos de bactérias, o que faz com que sejam potenciais veículos de 
disseminação de doenças e infecções à população ${ }^{3}$.

No ambiente hospitalar são realizados diversos procedimentos invasivos e não invasivos. Quando feitos sem as devidas precauções, podem aumentar a infecção cruzada, especialmente por materiais ou equipamentos contaminados com microrganismos patogênicos ${ }^{4}$.

A aquisição destes microrganismos ocorre, em geral, por meio da transmissão pelo contato das mãos dos profissionais com os pacientes e pelo contato direto do paciente com material ou ambiente contaminado ${ }^{5}$.

Um dos procedimentos rotineiros em uma unidade de internação é a realização de exames de raios $X$. Para tal, são utilizados chassis radiográficos não descartáveis, ou seja, estes cassetes são usados diversas vezes em pacientes distintos.

A disseminação das infecções relacionadas aos cuidados de saúde é complexa e multifatorial. Observa-se que a influência do ambiente pode ser maior nas Unidades de Terapia Intensiva (UTI), pois há a gravidade e instabilidade do quadro clínico dos pacientes com necessidade de cuidados intensivos, somando a fatores como limpeza, desinfecção, estrutura física, quantidades de equipamentos e superfícies ${ }^{6}$.

O Staphylococcus aureus é classificado como uma bactéria altamente patogênica, embora esteja presente como parte da microbiota da maioria dos indivíduos. É causador de diversos gêneros de infecções, tais como endocardites, pneumonias, septicemias entre outras. Pode ser encontrado em diversos sítios anatômicos, sendo os principais a cavidade nasal e as mãos?

O Staphylococcus aureus, além de ser uma das causas mais comuns de infecções nosocomiais, pode, ainda, evidenciar resistência aos antimicrobianos; o fenômeno pode ser mediado por plasmídeos ou codificado cromossomicamente. Fatores como internação em unidades de terapia intensiva (UTIs), hospitalização prolongada, procedimentos invasivos e exposição repetida a antibióticos propiciam o contato com o agente ${ }^{8}$.

As infecções hospitalares configuram-se como uma contínua preocupação para pacientes e profissionais da saúde, sendo necessárias constantes investigações e estudos sobre essa temática, com vista a essas considerações, apresenta-se como objetivos deste estudo:

Colloq Vitae 2018 jan-abr; 10(1): 29-34. DOI: 10.5747/cv.2018.v10.n1.v217

ISSN 1984-6436/@ 2018 - Publicado pela Universidade do Oeste Paulista.

Artigo Open Access sob uma licença CC BY-NC-ND (http://creativecommons.org/licenses/by-nc-nd/4.0/) investigar os chassis radiográficos como fontes de contaminação cruzada entre pacientes e verificar como são realizadas as radiografias nessa unidade quanto à prevenção e controle de infecção hospitalar, sugerindo a necessidade de protocolos eficientes quanto à desinfecção desses chassis radiológicos.

\section{METODOLOGIA}

Os objetos de estudo correspondem a dois chassis radiográficos $(18 \times 24 \mathrm{~cm})$ disponíveis no hospital para essa unidade de serviço.

Em cada dia de coleta, foram obtidas amostras para as culturas de microorganismos dos dois chassis ( 1 e $\mathrm{C} 2$ ), coletadas em três momentos diferentes: $\mathrm{MO}$ (início da rotina), M1 ( $2 \mathrm{~h}$ após início) e M2 (final da rotina), ou seja, foram obtidas seis amostras laboratoriais para as culturas dos chassis por dia de coleta, utilizando a técnica do uso de swabs (bastonete que contém um algodão na extremidade), fazendo uso de gorro, máscara, avental e luvas.

Nos dias de coleta, foi realizada a desinfecção dos chassis com álcool 70\% no início da rotina, deslizando em um único sentido durante três vezes. Após o processo de desinfecção, foram deslizados por rolamento, swabs estéreis umedecidos em soro fisiológico estéril na área central da superfície dos chassis, que ficam em contato com os pacientes e esse será considerado o momento zero (MO). Foi deslizado novamente swabs na área central para coleta no momento $\mathrm{M} 1$ após $2 \mathrm{~h}$ do início da rotina e o momento $\mathrm{M} 2$ no final da rotina.

As amostras laboratoriais para as culturas foram coletadas no período vespertino pela maior demanda de radiografias durante duas semanas, e semeadas em ágar sal Manitol, após encaminhas ao laboratório de microbiologia, onde ficaram incubadas em estufa bacteriológica entre $35^{\circ} \mathrm{C} \pm 2^{\circ} \mathrm{C}$ durante 18 a $24 \mathrm{~h}$. Passado esse período, foi realizada a leitura e a contagem de colônias e o resultado expresso em unidades formadoras de colônias de Staphylococcus spp (UFC/amostra) ${ }^{9}$.

As amostras que apresentarem a característica fermentação do meio de Manitol foram submetidas à coloração de Gram, para visualização da morfologia bacteriana e ao teste da catalase, para identificação da família. Em seguida, nas amostras catalase positivas, foi realizado o teste da coagulase, para identificação das espécies de Staphylococcus spp ${ }^{10}$. 
As amostras que não apresentaram crescimento bacteriano continuaram incubadas por mais 18 a $24 \mathrm{~h}$. E após $48 \mathrm{~h}$, as que continuaram sem crescimento foi liberado como resultado negativo, ou seja, não houve crescimento bacteriano ${ }^{11}$.

Os dados foram testados para normalidade pelo teste de Shapiro-Wilk. Para análise das unidades formadoras de colônias/amostra foi usado o teste de análise de variância para comparar as médias e desvios padrões nos grupos dentro de cada momento, com contrastes pelo método de Tukey. O nível de significância que será adotado é de $5 \%$.

\section{RESULTADOS}

Após a realização dos exames neste Hospital, em três momentos diferentes: MO (início da rotina), M1 (2 h após início) e M3 (final da rotina), foram observados presença de unidades formadoras de colônia (UFC) de Staphylococcus spp., sendo que no chassi 1 , $14,43 \%$ das colônias apresentaram a prova da coagulase positiva, e no chassi $2,1,37 \%$ indicando ser Staphylococcus aureus.

Tabela 1. Presença de microrganismos nos chassi radiográfico número 1.

\begin{tabular}{|c|c|c|c|c|c|c|}
\hline \multirow{2}{*}{ Dia } & \multicolumn{2}{|c|}{ UFC/amostra do M0 } & \multicolumn{2}{|r|}{ UFC/amostra do M1 } & \multicolumn{2}{|c|}{ UFC/amostra do M2 } \\
\hline & $n$ & Três momentos (\%) & $\mathrm{n}$ & Três momentos (\%) & $\mathrm{n}$ & Três momentos (\%) \\
\hline 10 & 0 & 0,00 & 6 & 1,60 & 24 & 6,42 \\
\hline 20 & 0 & 0,00 & 0 & 0,00 & 24 & 6,42 \\
\hline 3응 & 0 & 0,00 & 1 & 0,27 & 2 & 0,53 \\
\hline 4은 & 2 & 0,53 & 2 & 0,53 & 48 & 12,83 \\
\hline 5은 & 2 & 0,53 & 3 & 0,80 & 4 & 1,07 \\
\hline 60 & 0 & 0,00 & 2 & 0,53 & 0 & 0,00 \\
\hline 70 & 0 & 0,00 & 35 & 9,36 & 0 & 0,00 \\
\hline 80 & 3 & 0,80 & 22 & 5,88 & 22 & 5,88 \\
\hline 90 & 6 & 1,60 & 32 & 8,56 & 75 & 20,05 \\
\hline 10 은 & 0 & 0,00 & 1 & 0,27 & 3 & 0,80 \\
\hline 119 & 0 & 0,00 & 6 & 1,60 & 24 & 6,42 \\
\hline 120 & 0 & 0,00 & 11 & 2,94 & 14 & 3,74 \\
\hline
\end{tabular}

UFC/amostra (Unidades formadoras de colônia Staphylococcus spp./amostra).

Tabela 2. Presença de microrganismos no chassi radiográfico número 2.

\begin{tabular}{|c|c|c|c|c|c|c|}
\hline \multirow{2}{*}{ Dia } & \multicolumn{2}{|c|}{ UFC/amostra do MO } & \multicolumn{2}{|c|}{ UFC/amostra do M1 } & \multicolumn{2}{|c|}{ UFC/amostra do M2 } \\
\hline & $\mathrm{n}$ & Três momentos (\%) & $\mathrm{n}$ & Três momentos (\%) & $\mathrm{n}$ & Três momentos (\%) \\
\hline 1으 & 1 & 0,27 & 18 & 4,95 & 188 & 51,65 \\
\hline 20 & 0 & 0,00 & 25 & 6,87 & 6 & 1,65 \\
\hline 3응 & 0 & 0,00 & 5 & 1,37 & 4 & 1,10 \\
\hline 40 & 1 & 0,27 & 2 & 0,55 & 4 & 1,10 \\
\hline 5응 & 0 & 0,00 & 5 & 1,37 & 5 & 1,37 \\
\hline 60 & 0 & 0,00 & 0 & 0,00 & 1 & 0,27 \\
\hline 70 & 0 & 0,00 & 0 & 0,00 & 28 & 7,69 \\
\hline 80 & 0 & 0,00 & 5 & 1,37 & 1 & 0,27 \\
\hline 9응 & 0 & 0,00 & 4 & 1,10 & 9 & 2,47 \\
\hline 10 은 & 0 & 0,00 & 1 & 0,27 & 1 & 0,27 \\
\hline 119 & 0 & 0,00 & 5 & 1,37 & 35 & 9,62 \\
\hline $12 \%$ & 0 & 0,00 & 4 & 1,10 & 6 & 1,65 \\
\hline
\end{tabular}

UFC/amostra (Unidades formadoras de colônia de Staphylococcus spp./amostra). 
No decorrer dos dias de coleta, comparando os três momentos de todos os chassis, foram observadas no chassi 1 apresentaram diferenças estatísticas significativas nos valores das unidades formadoras de colônia (UFC) de Staphylococcus spp. $(\mathrm{p}<0,05)$ entre os momentos 0-2, e comparando os momentos 0-1, e 1-2 não houve diferenças estatísticas entre o nível de contaminação por Staphylococcus spp.

No chassi 2, não apresentaram diferenças estatísticas significativas nos valores de unidades formadoras de colônia (UFC) do Staphylococcus spp. nos três momentos de estudo.

\section{DISCUSSÃO}

Se não for realizada a limpeza adequada, desinfecção ou esterilização desses chassis radiológicos hospitalares, estes se tornam fonte de contaminação e oferecem riscos de aquisição de microrganismos, tanto para os pacientes como para os profissionais da saúde ${ }^{12}$.

A transmissão de $S$. aureus pode acontecer por contato direto. Esse portador de $S$. aureus exerce papel importante na epidemiologia e na patogênese da infecção, pois é o maior fator de risco para desenvolvimento de infecções hospitalares e adquiridas na comunidade ${ }^{13}$.

A frequência de Staphylococcus spp. encontrada no presente estudo foram no final da rotina $M 2$, sendo no chassi $1,64,17 \%$, e no chassi $2,79,12 \%$. Tais porcentagens podem ser devido a maior superfície de contato entre a pele dos pacientes e ao não estabelecimento de um protocolo eficiente de limpeza dos chassis ${ }^{14}$. Microrganismos da microbiota normal da pele como Staphylococcus spp. das mãos e do ambiente, podem ser patogênicos principalmente em casos de imunodeficiência, lesões, deficiência das barreiras físicas do organismo, deficiência de nutrientes e outros ${ }^{15}$.

No estudo realizado foram observados a presença de Staphylococcus coagulase negativa em $85,57 \%$ no chassi 1 , e $98,63 \%$ no chassi 2 . Estes microrganismos não oferecerem riscos tão grandes como outras espécies de Staphylococcus, mas podem também vir a se tornar patogênicos, dependendo do estado do hospedeiro, ou seja, uma imunodepressão ou uma via de abertura (corte na pele, por exemplo), assim, tal infecção pode vir a trazer problemas sérios de saúde ${ }^{16}$.

$$
\text { Embora tenhamos isolados }
$$

Staphylococcus coagulase negativa na maioria das amostras analisadas, obtivemos coagulase positiva em $14,43 \%$ no chassi 1 , e no chassi 2 , $1,37 \%$. Evidências na literatura mostram que, no isolamento de bactérias provenientes de diferentes sítios de inserção do corpo humano, o Staphylococcus coagulase negativa (SCN) é a espécie mais comumente encontrada e o Staphylococcus aureus, a mais virulenta. Estes microrganismos são considerados importantes agentes de infecções nosocomiais no Brasil, ocasionando, deste modo, a necessidade de uma identificação rápida e a adoção de um protocolo eficiente de assepsia dos chassis radiográficos ${ }^{17}$.

No nosso estudo, observando a contaminação bacteriana por Staphylococcus spp. entre o M0 e o M2 do chassi 1 , houve um aumento do crescimento bacteriano, mostrando que esse chassi foi utilizado por vários pacientes, possibilitando a contaminação de superfície, o que causaria infecções em organismos debilitados. Alguns estudos sugerem uma ligação entre infecções e superfícies contaminadas; outros pesquisadores sugerem ainda que as mãos contaminadas sejam um possível veículo de processos infecciosos ${ }^{18}$.

A contaminação bacteriana entre os momentos $M 0$ e $M 1$, e $M 1$ e $M 2$ não houve diferenças de colonização bacteriana nesses grupos nos dois chassis radiográficos, indicando que a descontaminação com álcool $70 \%$ é útil. Entretanto, não é efetiva. 0 álcool etílico muito utilizado em superfícies e instrumentos, assim como na pele, como antisséptico, é considerado desinfetante de nível intermediário. Seu efeito corresponde à desnaturação de proteínas e à dissolução de gorduras, o que permite a atividade antimicrobiana. Porém, seu uso não é efetivo na presença de líquidos biológicos, pois quando estes se aderem à superfície do material, funcionam como uma barreira mecânica à ação do álcool sobre os microrganismos ${ }^{19}$.

\section{CONCLUSÃO}

O estudo identificou que os chassis radiográficos devem ser considerados como fômites durante a realização dos exames de raios $X$ entre pacientes, pois existem patógenos nesses chassis após a realização destas radiografias no setor deste Hospital de Ensino. Além do mais, não é realizada na rotina a desinfecção destes objetos reutilizáveis e que entram em contato direto com os pacientes durante os referidos exames. 
Diante dos resultados, o estudo propõe a padronização de um procedimento operacional de higienização para limpeza dos chassis radiográficos na tentativa de minimizar o risco de contaminação bacteriana por Staphylococcus spp.

\section{CONFLITO DE INTERESSES}

Os autores declaram não haver qualquer potencial conflito de interesse que possa interferir na imparcialidade deste trabalho científico.

\section{REFERÊNCIAS}

1. Marques PB, Carneiro FMC, Ferreira AP. Perfil bacteriano de cultura de ponta de cateter venoso central. Rev Pan-Amaz Saúde. 2011;2(1):53-8. DOI: https://doi.org/10.5123/S2176$\underline{62232011000100006}$

2. Pacheco Junior FB, Sousa CF, Rocha TJM, Reys JRM, Rodrigues MML. Frequência de bactérias patogênicas nos computadores de uma instituição privada de ensino superior de Maceió-AL. Rev Bio Farm. 2011;6(2):100-7.

3. Nolla AC, Cantos GA. Relação entre a ocorrência de enteroparasitoses em manipuladores de alimentos e aspectos epidemiológicos em Florianópolis, Santa Catarina, Brasil. Cad Saúd Públic 2005;Abr;21(2):641-5. DOI:

\section{$\underline{311 \times 2005000200033}$}

4. Pereira LM, Madeira MZA, Júnior FJGS, Deolindo VS, Trabasso P. Contaminação de cassetes radiográficos em hospital privado: uma contribuição da enfermagem. J Health Sci Inst. 2012;30(3):249-54.

5. Oliveira AC, Cardoso CS, Mascarenhas D. Precauções de contato em Unidade de Terapia Intensiva: fatores facilitadores e dificultadores para adesão dos profissionais. Rev Esc Enferm USP. 2010;44(1):161-5. DOI: https://doi.org/10.1590/S0080$\underline{62342010000100023}$

6. Oliveira AC, Damasceno QS. Superfícies do ambiente hospitalar como possíveis reservatórios de bactérias resistentes. Rev EsC Enferm USP. 2010;44(4):1118-23. DOI: https://doi.org/10.1590/S0080-62342010000400038

7. Cavalcanti SMM, França ER, Vilela MA, Montenegro F, Cabral C, Medeiros ACR. Estudo comparativo da prevalência de Staphylococcus aureus importado para as unidades de terapia intensiva de hospital universitário, Pernambuco, Brasil. Rev Bras Epidemiol.
2006;9(4):436-46.

DOI: https://doi.org/10.1590/S1415-790X2006000400004

8. Martins JPO, Porto ER, Silva RN, Pinhati HMS. Prevalência de Staphylococcus aureus Resistente à Meticilina, Isolado em Hemoculturas de Pacientes Internados em Alguns Hospitais do Distrito Federal, Brasil. Brasilia Med. 2009;46(2):125-30.

9. Ministério da Saúde. Agência Nacional de Vigilância Sanitária. Higienização das mãos em serviços de saúde. Brasília; 2009.

10. Koneman EW, Allen SD, Janda WM, Schreckenberger PC, Winn WC. Diagnóstico Microbiológico. 6.ed. Rio de Janeiro: Medsi; 2008.

11. Ministério da Saúde. Agência Nacional de Vigilância Sanitária. Manual de Microbiologia Clínica para o Controle de Infecção em Serviços de Saúde. Salvador; 2004.

12. Anders PS, Tipple ACFV, Pimenta FC. Kits para aerossol em um serviço de saúde: uma análise microbiológica após reprocessamento. Rev Esc Enferm USP. 2008;42(2):276-81.

DOI:

http://dx.doi.org/10.1590/S0080$\underline{62342008000200010.276-81}$

13. Cavalcanti SMM, França ER, Vilela MA, Montenegro F, Cabral C, Medeiros ACR. Estudo comparativo da prevalência de Staphylococcus aureus importado para as unidades de terapia intensiva de hospital universitário, Pernambuco, Brasil. Rev Bras Epidemiol. 2006;9(4):436-46. DOI: https://doi.org/10.1590/S1415-790X2006000400004

14. Russo EMA, Carvalho RCR, Lorenzo JL, Garone NN, Cardoso MV, Grossi E. Avaliação da intensidade de contaminação de pontas de seringa tríplice. Pesq Odontol Bras. 2000;14(3): 243-7. DOI: https://doi.org/10.1590/S1517-74912000000300010

15. Bonato BS, Castro FF; Carvalho TC, Helena RPG. Oculares de microscópios podem ser veículos de contaminação? News Lab Franca. 2007;81:98-104.

16. Nelson J, Bivens A, Shinn A, Wanzer L, Kasper C. Microbial Flora on Operating Room Telephones, Association of operating room nurses. AORN J. 2016;83(3):607-26. https://doi.org/10.1016/S0001-2092(06)60190-7

17. Marques PB, Carneiro FMC, Ferreira AP. Perfil bacteriano de cultura de ponta de cateter venoso central. Rev Pan-Amaz Saúd. 2011;2(1):53-8. DOI: https://doi.org/10.5123/S2176$\underline{62232011000100006}$ 
18. Bonato BS, Castro FF; Carvalho TC, Helena RPG. Oculares de microscópios podem ser veículos de contaminação? News Lab Franca. 2007;81:98-104.

19. Venturelli AC, Torres FC, Almeida-Pedrin RR, Almeida RR, Almeida MR, Ferreira FPC. Avaliação microbiológica da contaminação residual em diferentes tipos de alicates ortodônticos após desinfecção com álcool 70\%. Rev Dent Press Ortodon Ortop Facial. 2009;14(4):43-52. DOI: https://doi.org/10.1590/S1415-54192009000400005

Recebido para publicação em 09/11/2016

Revisado em 22/03/2018

Aceito em 10/05/2018 